\title{
Enzymes involved in organellar DNA replication in photosynthetic eukaryotes
}

\author{
Takashi Moriyama ${ }^{1,2}$ and Naoki Sato ${ }^{1,2}$ * \\ ${ }^{1}$ Department of Life Sciences, Graduate School of Arts and Sciences, The University of Tokyo, Tokyo, Japan \\ 2 Japan Science and Technology Agency - Core Research for Evolutional Science and Technology, Tokyo, Japan
}

\section{Edited by:}

Thomas Pfannschmidt, Université Joseph Fourier Grenoble, France

\section{Reviewed by:}

Ján A. Miernyk, University of

Missouri, USA

Mee-Len Chye, The University of Hong Kong, China

*Correspondence:

Naoki Sato, Department of Life Sciences, Graduate School of Arts and Sciences, The University of Tokyo, Komaba 3-8-1, Meguro-ku, Tokyo 153-8902, Japan

e-mail: naokisat@bio.c.u-tokyo.ac.jp
Plastids and mitochondria possess their own genomes. Although the replication mechanisms of these organellar genomes remain unclear in photosynthetic eukaryotes, several organelle-localized enzymes related to genome replication, including DNA polymerase, DNA primase, DNA helicase, DNA topoisomerase, single-stranded DNA maintenance protein, DNA ligase, primer removal enzyme, and several DNA recombination-related enzymes, have been identified. In the reference Eudicot plant Arabidopsis thaliana, the replication-related enzymes of plastids and mitochondria are similar because many of them are dual targeted to both organelles, whereas in the red alga Cyanidioschyzon merolae, plastids and mitochondria contain different replication machinery components. The enzymes involved in organellar genome replication in green plants and red algae were derived from different origins, including proteobacterial, cyanobacterial, and eukaryotic lineages. In the present review, we summarize the available data for enzymes related to organellar genome replication in green plants and red algae. In addition, based on the type and distribution of replication enzymes in photosynthetic eukaryotes, we discuss the transitional history of replication enzymes in the organelles of plants.

Keywords: plastids, mitochondria, organellar genome, replication

\section{INTRODUCTION}

Plastids and mitochondria are semi-autonomous organelles that contain their own genomes, encoding the genes necessary to perform their respective metabolic functions. These organellar genomes are replicated by specific enzymes, such as DNA polymerase, DNA primase, and DNA helicase, as occurs in bacteria and the nuclei of eukaryotes. In contrast, plant organellar genomes do not encode these replicative proteins, and are instead replicated by nucleus-encoded enzymes that are transported to the organelles. However, the mechanism of plant organellar genome replication is not clearly understood because more than one mode of replication is possible and include recombination-dependent, double D-loop, and rolling circle replication mechanisms (reviewed in Maréchal and Brisson, 2010; Nielsen et al., 2010; Gualberto et al., 2014).

Mitochondria and plastids are thought to have been acquired through endosymbiotic events with ancestors of $\alpha$-proteobacteria and cyanobacteria, respectively. Studies of bacterial replication enzymes (Langston et al., 2009; Sanyal and Doig, 2012) have shown that homologs of these enzymes also function in plant organelles. In bacterial DNA replication, DnaB helicase unwinds double-stranded DNA (dsDNA) at the replication fork, and the unwound DNA is then prevented from re-annealing with other single-stranded DNAs (ssDNAs) by single-stranded DNA-binding protein (SSB). A type II DNA topoisomerase (gyrase) consisting of $A$ and $B$ subunits alleviates the mechanical strain of unwound DNA. DnaG primase synthesizes an RNA primer, which is elongated by DNA polymerase III and is then removed by nick translation with $5^{\prime}-3^{\prime}$ exonuclease and the polymerase activity of
DNA polymerase I (PolI). The nicked DNA is combined by the $\mathrm{NAD}^{+}$-dependent DNA ligase LigA.

All of the enzymes involved in mitochondrial DNA replication in vertebrates have been identified (Arnold et al., 2012; Kasiviswanathan etal., 2012). DNA polymerase $\gamma$ (Pol $\gamma$ ) functions in the replication and repair of animal mitochondrial DNA. Animal Pol $\gamma$ consists of two subunits: a large subunit with DNA polymerase and $3^{\prime}-5^{\prime}$ exonuclease activities, and a small subunit that functions in primer recognition and enhances processivity (Kaguni, 2004; Wanrooij and Falkenberg, 2010). The animal mitochondrial primase, POLRMT, which has homology to the RNA polymerase of T3/T7 phage, was recently indicated to function in both primer synthesis and transcription, although it was previously thought to function only in transcription (Wanrooij et al., 2008). Plants also have homolog(s) of T3/T7 phage RNA polymerase, which are named RPOTs (RNA polymerase of the T3/T7 type) and are localized to plastids and/or mitochondria, where they function in transcription (Kühn et al., 2007). Mitochondrial helicase is called TWINKLE and has homology to the gp protein of T7 phage, which contains primase and helicase domains at the $N$ - and $C$-termini, respectively. However, although the TWINKLE found in bikonts (plants and protists) has both primase and helicase activities, animal TWINKLE only shows helicase activity (Shutt and Gray, 2006). A number of other replication-related enzymes, including topoisomerases 1 and 3a, SSB, ligase 3 , and RNase $\mathrm{H} 1$, have also been identified in human mitochondria. An in vitro reconstituted mitochondrial replisome composed of Pol $\gamma$, TWINKLE, and SSB displayed rolling-circle replication with high processivity (Korhonen et al., 2004). 
Several of the replicative enzymes found in bacteria and animal mitochondria are also encoded by plant nuclear genomes. In addition to these common enzymes, a number of plant-specific enzymes for DNA replication and recombination have recently been identified, and their subcellular localization has been examined in both plants and algae. In this article, we summarize the current knowledge on enzymes related to organellar replication in photosynthetic eukaryotes and also discuss the evolution of these replication-related enzymes based on their distribution in photosynthetic eukaryotes.

\section{REPLICATION DNA POLYMERASE, POP HISTORY OF STUDIES ON ORGANELLAR DNA POLYMERASES IN PLANTS}

DNA replication activity was first detected in isolated organelles from plants, yeasts, and animals in the late 1960s (Wintersberger, 1966; Parsons and Simpson, 1967; Spencer and Whitfeld, 1967; Tewari and Wildman, 1967). In the following decade, DNA polymerases were purified from isolated chloroplasts and mitochondria of various photosynthetic eukaryotes (summarized in Moriyama and Sato, 2013). Biochemical data suggested that plant organellar and $\gamma$-type DNA polymerases, which are responsible for replication of the mitochondrial genome in fungi and animals (Lecrenier and Foury, 2000; Kaguni, 2004), had similar optimal enzymatic conditions, particularly $\mathrm{pH}$ and the concentration of monovalent and divalent ions, sensitivity to DNA polymerase inhibitors, molecular size, and template preference. Despite such biochemical evidence, no gene encoding a homolog of Pol $\gamma$ has been found in the sequenced genomes of bikonts, including those of plants and protists, and the organellar DNA polymerase in photosynthetic organisms remains unidentified. Sakai et al. (1999) and Sakai (2001) detected DNA synthetic activity in the nucleoid fraction isolated from chloroplasts and mitochondria of tobacco and determined that the apparent molecular mass of the enzyme exhibiting the activity was similar to the Klenow fragment of PolI in Escherichia coli. This finding led to the identification of a gene(s) encoding a DNA polymerase with distant homology to E. coli PolI in the genomes of bikonts. The identified DNA polymerase was first isolated from plastids of rice, and its localization was confirmed by immunoblot analysis of isolated plastids (Kimura et al., 2002). Subsequent studies using GFP-fusion proteins and/or immunoblotting demonstrated that the polymerases, which were named PolI-like, PolI or Pol $\gamma$, are localized to both plastids and mitochondria in Arabidopsis thaliana and tobacco (Christensen et al., 2005; Mori et al., 2005; Ono et al., 2007; Parent et al., 2011; Cupp and Nielsen, 2013). We also identified this type of DNA polymerase in algae and ciliates (Moriyama et al., 2008, 2011,2014). In these reports, phylogenetic analysis of Family A DNA polymerases revealed that plant organellar DNA polymerases belong to a clade that is distinct from that of bacterial PolI and Poly (Figure 1). In addition, red algae were found to encode a DNA polymerase with high homology to E. coli PolI (Moriyama et al., 2008). Therefore, we proposed that this type of organellar DNA polymerase be named POP (plant and protist organellar DNA polymerase), because the genes encoding the polymerases are present in both photosynthetic eukaryotes and protists.

\section{ENZYMATIC CHARACTERISTICS OF POPS}

\section{Characterization of DNA polymerase activity of POPS}

The DNA polymerase activity of POPs has been characterized using recombinant (Kimura et al., 2002; Ono et al., 2007; Takeuchi et al., 2007) and native proteins purified from Cyanidioschyzon merolae (red alga) and isolated mitochondria of Tetrahymena thermophila (Moriyama et al., 2008, 2011). The optimal KCl concentration for POP polymerase activity is $50-150 \mathrm{mM}$. POPs also show divalent metal ion-dependent activity, and the optimal $\mathrm{MgCl}_{2}$ concentration for their activity is $2.5-5 \mathrm{mM}$. POPs exhibit the highest activity with poly $(\mathrm{dA}) / \mathrm{oligo}(\mathrm{dT})$ as a template, rather than with activated calf thymus DNA. However, poly(rA)/oligo(dT) can also be used as a template, indicating that POPs have reverse transcriptase activity, similar to Pol $\gamma$, although the in vivo role of this activity has not been elucidated.

DNA polymerase enzymes bind to and dissociate from template DNA repeatedly during the replication or repair process. The number of synthesized nucleotides added by the DNA polymerase per one binding event is defined as processivity. POPs show markedly high processivity values, ranging from 600 to $900 \mathrm{nt}$ for recombinant rice POP and 1,300 nt for Cyanidioschyzon merolae POP (Figure 2, Moriyama et al., 2008). In comparison, E. coli PolI has mid-range processivity of $<15 \mathrm{nt}$ (Takeuchi et al., 2007). The Cyanidioschyzon merolae genome encodes a PolI gene $(\mathrm{CmPolI})$ having high homology with E. coli PolI, and CmPolI also has midrange processivity of $<70 \mathrm{nt}$ (Moriyama et al., 2008). Alignment analysis of POPs with other Family A DNA polymerases revealed that POP proteins have additional sequences that are involved in DNA binding and synthesis activities, suggesting that the high processivity of POPs might be attributable to these extra sequences (Takeuchi et al., 2007). In animals, an accessory subunit (Pol $\gamma \mathrm{B}$ ) of Pol $\gamma$ enhances the processivity of Pol $\gamma \mathrm{A}$. For example, the processivities of the Drosophila Pol $\gamma$ A subunit and a Pol $\gamma$ holoenzyme consisting of Pol $\gamma \mathrm{A}$ and Pol $\gamma \mathrm{B}$ are $<40 \mathrm{nt}$ and $>1,000 \mathrm{nt}$, respectively (Williams et al., 1993). In contrast, POPs show high processivity as a single subunit enzyme, and to our knowledge, no accessory proteins associated with POP have been identified.

\section{Sensitivity to DNA polymerase inhibitors}

The effect of inhibitors, such as aphidicolin, $N$-ethylmaleimide (NEM), dideoxyTTP (ddTTP), and phosphonoacetate (PAA), on the DNA synthesis activity of POPs was evaluated (Kimura et al., 2002; Ono et al., 2007; Moriyama et al., 2008, 2011). Aphidicolin is an inhibitor of eukaryotic nuclear DNA polymerases $\alpha, \delta$, and $\varepsilon$ (Holmes, 1981; Weiser et al., 1991), and did not inhibit POP activity (Moriyama et al., 2008). NEM is an inhibitor of DNA polymerases $\alpha, \gamma, \delta$, and $\varepsilon$ (Chavalitshewinkoon-Petmitr et al., 2000), and also did not inhibit POP. ddTTP, which severely impairs the activity of DNA polymerases $\beta$ and $\gamma$ (Kornberg and Baker, 1992), had various inhibitory effects on POP depending on the organism, with the half maximal inhibitory concentrations $\left(\mathrm{IC}_{50}\right)$ ranging from 4 to $615 \mu \mathrm{M}$ for the POPs of A. thaliana, Cyanidioschyzon merolae, and the ciliate Tetrahymena (Moriyama et al., 2011). PAA was originally identified as an inhibitor of viral DNA polymerases and reverse transcriptases, and functions by interacting with pyrophosphate binding sites, leading to an alternative reaction pathway (Leinbach etal., 1976; Shiraki et al., 1989). PAA 


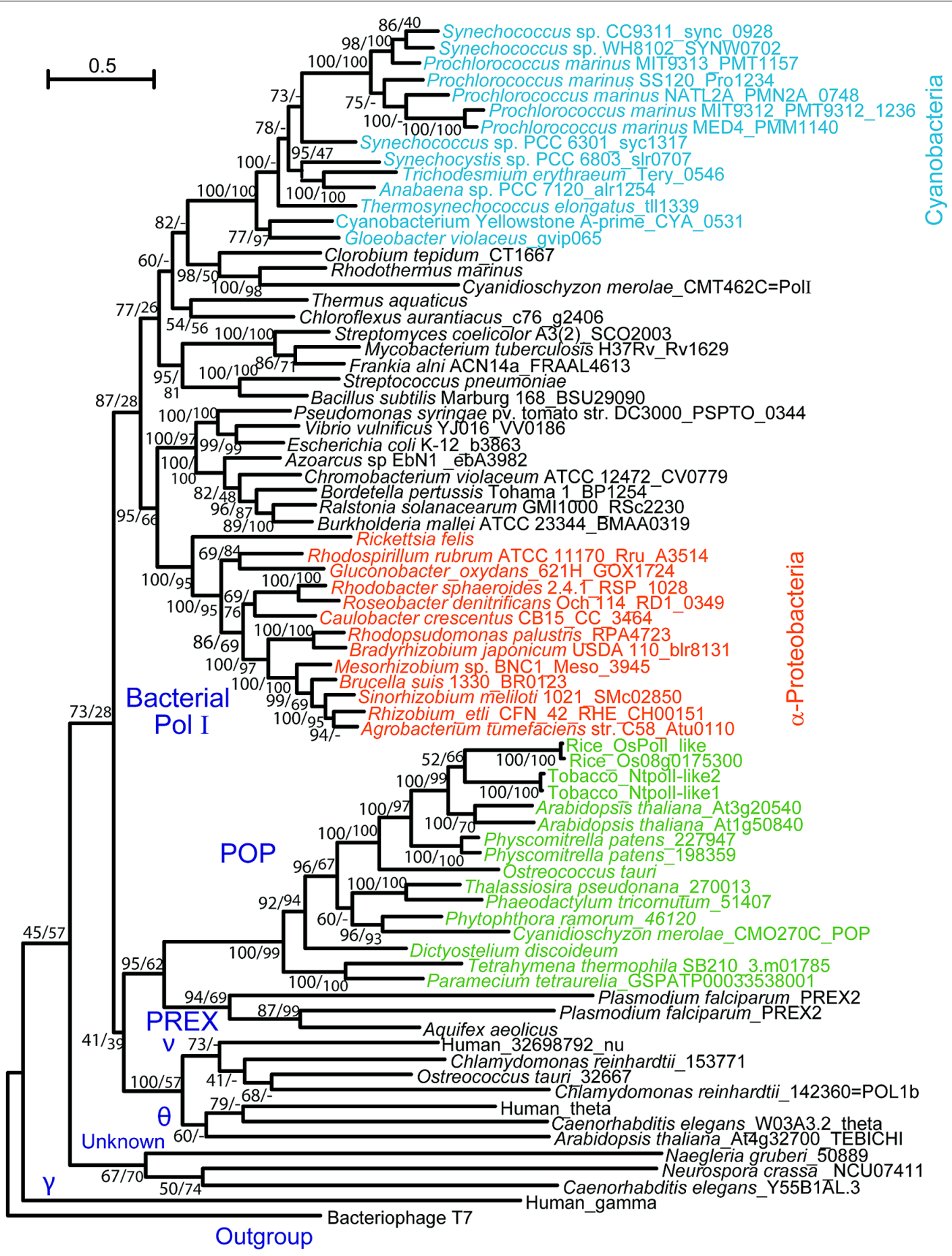

FIGURE 1 | Phylogenetic tree of Family A DNA polymerases. Reproduced from Moriyama et al. (2014) with permission.

severely inhibits the activity of POPs, with $\mathrm{IC}_{50}$ values of $1-25 \mu \mathrm{M}$ (Moriyama et al., 2011). Because PAA at low concentrations does not inhibit other Family A DNA polymerases, such as PolI and Pol $\gamma$, sensitivity to PAA is a useful marker for the classification of organelle-localized DNA polymerases in unsequenced eukaryotes (Moriyama et al., 2011).

\section{$3^{\prime}-5^{\prime}$ exonuclease activity}

Plant and protist organellar DNA polymerases have a $3^{\prime}-5^{\prime}$ exonuclease domain at the $N$-terminus consisting of three conserved regions, Exo I, Exo II, and Exo III. This exonuclease activity was shown in rice (Takeuchi et al., 2007) and Cyanidioschyzon (Moriyama et al., 2008). In rice POP, a mutant protein containing 


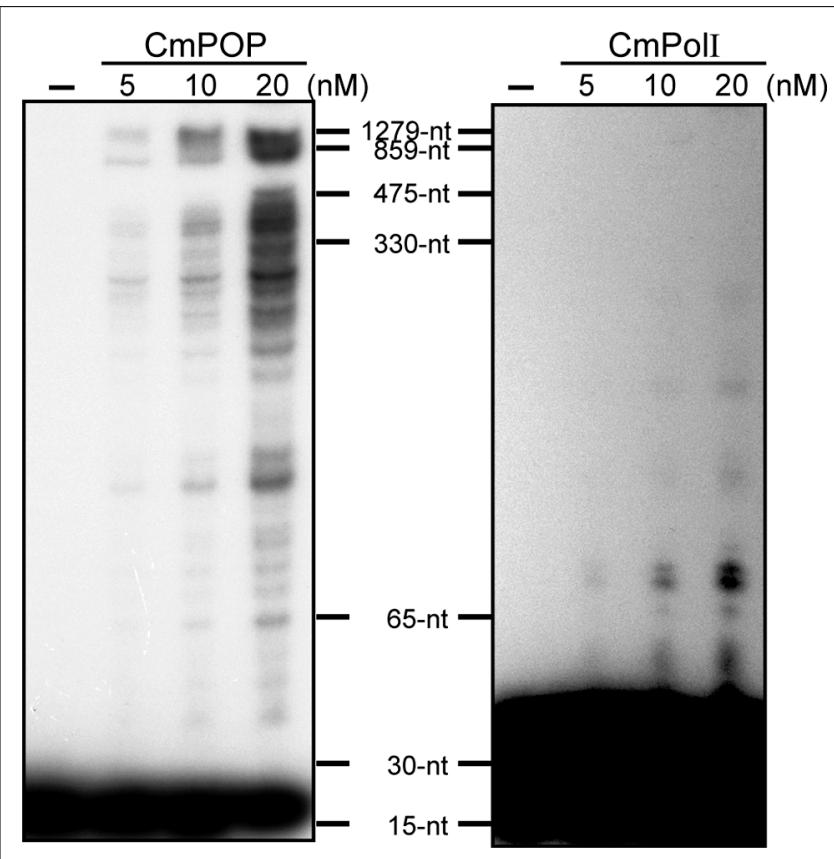

FIGURE 2 | Processivity of CmPOP and CmPoll. Reactions were performed in reaction buffer $(50 \mathrm{mM}$ Tris- $\mathrm{HCl}[\mathrm{pH}$ 8.0], $5 \mathrm{mM} \mathrm{MgCl}, 1 \mathrm{mM}$ DTT, $0.01 \%$ BSA, $50 \mu \mathrm{M}$ dATP, $50 \mu \mathrm{M}$ dTTP, $50 \mu \mathrm{M}$ dGTP, $50 \mu \mathrm{M}$ dCTP, and $10 \mathrm{nM}{ }^{32} \mathrm{P}$-labeled M13mp18-M1) at $37^{\circ} \mathrm{C}$ for $5 \mathrm{~min}$. The reaction products were analyzed in $5 \%$ polyacrylamide gels containing $7 \mathrm{M}$ urea. Reproduced from Moriyama etal. (2008) with permission.

a replacement of Asp365 with Ala in the Exo II domain lost $3^{\prime}-5^{\prime}$ exonuclease activity. In terms of $3^{\prime}-5^{\prime}$ exonuclease proofreading activity, rice POP exhibited a relatively high fidelity at a base substitution rate of $10^{-4}$ to $10^{-5}$ (Takeuchi et al., 2007).

\section{EXPRESSION OF POP IN PLANTS}

In tobacco BY-2 cells, the amount of POP transcripts and proteins increases at the initial phase of plastidial and mitochondrial DNA replication (Ono etal., 2007). The spatial expression patterns of POPs were analyzed in $A$. thaliana and rice by in situ hybridization, which revealed that POP genes are strongly expressed in the apical meristems of roots and shoots, leading to high POP protein levels in these tissues (Kimura et al., 2002; Mori et al., 2005). In A. thaliana, the expression of two POPs, AtPOP1 (At1g80840) and AtPOP2 (At3g20540), were compared by quantitative RT-PCR (Cupp and Nielsen, 2013). The analysis demonstrated that AtPOP1 is mainly expressed in rosette leaves, whereas AtPOP2 is predominantly found in the meristems of roots and shoots.

\section{EXPRESSION OF POP IN ALGAE}

The unicellular red alga Cyanidioschyzon merolae contains a single plastid and mitochondrion (Matsuzaki et al., 2004), whose division cycles are synchronized with the cell cycle. In synchronous cultures of Cyanidioschyzon merolae established using light-dark cycles (Suzuki et al., 1994), cells divide at $\sim 12$ h from the beginning of the light phase, and nuclear DNA increases at or just before the M-phase. Replication of the mitochondrial genome appears to be at least partially synchronized with the cell cycle, as mitochondrial DNA begins to replicate from the light phase, and reaches a two-fold increase at or near the M-phase. In contrast, plastid DNA increases gradually throughout the entire cell cycle, even after cell division is complete (Moriyama et al., 2010). In contrast to land plants, which typically encode two or more copies of POP, Cyanidioschyzon merolae only has a single POP. The mRNA level of CmPOP changes during the cell cycle and reaches a peak that correlates with the rise in the mitotic index (Moriyama et al., 2008). However, the protein level of POP remains nearly unchanged throughout the cell cycle, with only small increases and decreases occurring during the light and dark phases, respectively. The observed expression of CmPOP is consistent with the results of organellar DNA replication during the cell cycle of Cyanidioschyzon merolae.

\section{PHENOTYPES OF POP MUTANTS IN PLANTS}

POP mutants of $A$. thaliana have been characterized by two research groups (Parent et al., 2011; Cupp and Nielsen, 2013). The A. thaliana genome encodes two POPs, AtPOP1 and AtPOP2, which are both localized to plastids and mitochondria. Double mutation of AtPOP1 and AtPOP2 was lethal, whereas each single mutant showed reduced DNA levels in both plastids and mitochondria. Additionally, the Atpop2 mutant displayed high sensitivity to ciprofloxacin, an inducer of DNA double-strand breaks. These results indicate that two distinct POPs are involved in genome replication for plastids and mitochondria, and that AtPOP2 also functions in DNA repair in both organelles.

\section{OTHER REPLICATION ENZYMES OF ORGANELLAR GENOMES DNA PRIMASE AND HELICASE}

DNA helicase unwinds dsDNA to allow DNA replication by DNA polymerase. In E. coli, primase synthesizes an RNA primer at the origin of replication in the leading strand and every $\sim 1 \mathrm{~kb}$ in the lagging strand. TWINKLE (T7 gp4-like protein with intramitochondrial nucleoid localization), which is a homolog of the T7 phage gp4 protein with primase and helicase activities, was originally reported to function as a hexameric DNA helicase in human mitochondria (Spelbrink et al., 2001). In A. thaliana, TWINKLE functions as a DNA helicase and primase (Diray-Arce etal., 2013), and was shown to be localized to both chloroplasts and mitochondria by GFP-tagging experiments (Carrie et al., 2009). Dual-targeted enzymes to the mitochondria and chloroplasts of plants are summarized in the review by Carrie and Small (2013). In an assay using single-stranded M13 DNA as a template, a recombinant TWINKLE protein of $A$. thaliana (AtTWINKLE) showed ATP-dependent helicase and primase activities, synthesizing RNA primers of $>15 \mathrm{nt}$ that were then extended by E. coli PolI into high-molecular-weight DNA (Diray-Arce et al., 2013). The protein and mRNA of AtTWINKLE are mainly expressed in the meristem and young leaves, which is similar to the expression pattern of $A$. thaliana POPs, particularly AT3G20540. The A. thaliana genome encodes a second TWINKLE gene whose protein product only has the $N$-terminal primase domain of TWINKLE and is localized to chloroplasts, 
according to unpublished data in the review by Cupp and Nielsen (2014).

Red algae also have a TWINKLE protein; however, it is localized to only mitochondria (Moriyama etal., 2014). Red algae and diatoms have a plastid-encoded DnaB helicase and a nucleus-encoded DnaG primase. In our analysis using GFP in Cyanidioschyzon merolae, DnaG was localized to the plastid. We also confirmed the plastid-localization of DnaG in the red alga Porphyridium purpureum. Based on these data, it appears that red algae and diatoms, the latter of which is thought to have originated from the secondary endosymbiosis with a red alga, utilize DnaB/DnaG in plastids and TWINKLE in mitochondria.

\section{DNA TOPOISOMERASE}

Arabidopsis thaliana has a single gyrase A (AtGYRA) that is localized to both plastids and mitochondria, and has two gyrase B enzymes that are localized to either chloroplasts (AtGYRB1) or mitochondria (AtGYRB2; Wall et al., 2004). T-DNA insertion mutation of AtGYRA leads to an embryo-lethal phenotype, whereas T-DNA insertion mutations of both plastidial AtGYRB1 and mitochondrial AtGYRB2 result in seedling-lethal phenotypes (Wall et al., 2004). In Nicotiana benthamiana, virusinduced silencing of the genes encoding GYRA and GYRB resulted in abnormal nucleoid content and structure of chloroplasts and mitochondria (Cho et al., 2004). A. thaliana also encodes a gyrase B-like gene, GYRB3; however, it is recently reported that AtGYRB3 does not encode a gyrase subunit, as AtGYRB3 showed no supercoiling activity and did not interact with AtGYRA (Evans-Roberts et al., 2010). In addition to gyrases, plant organelles contain A-type topoisomerase I, which is a homolog of bacterial topoisomerase I (TopA). Based on localization analysis using a GFP-fusion protein, AtTOP1 was shown to be localized to both chloroplasts and mitochondria (Carrie et al., 2009).

The genome of Cyanidioschyzon merolae encodes genes for GYRA and GYRB, which are localized only to the plastid (Moriyama et al., 2014). Similarly, Cyanidioschyzon merolae TOP1 (type IA) is also localized only to the plastid. To search for mitochondrial topoisomerases, we examined the subcellular localization of topoisomerases encoded in the Cyanidioschyzon merolae genome, and showed that a homolog of eukaryotic TOP2 is targeted to mitochondria. To date, organellar localization of eukaryotic TOP2 has not been reported in plants. In Cyanidioschyzon merolae, the gyrase specific inhibitor nalidixic acid arrests not only replication of the plastid genome, but also that of the mitochondrial and nuclear genomes (Itoh et al., 1997; Kobayashi etal., 2009). The localization results of gyrases in Cyanidioschyzon merolae suggest that defective plastid replication leads to the arrest of mitochondrial and nuclear replication by a yet unknown mechanism.

\section{DNA LIGASE}

DNA ligase is required for DNA replication, repair, and recombination, as it seals nicked-DNA ends of single-stranded breaks or joins DNA ends after double-stranded breaks. Four DNA ligases have been identified in the A. thaliana genome. A. thaliana DNA ligase 1 (AtLIG1) is targeted to either the mitochondria or the nucleus when the gene transcript is translated from the first and second initiation codons, respectively (Sunderland et al., 2004, 2006). AtLIG1 is expressed in all tissues of A. thaliana, but higher transcript levels are found in young leaves and tissues containing meristem (Taylor et al., 1998). Plastid-targeting of AtLIG1 was not observed for any AtLIG1-GFP constructs translated from possible initiation codons, and the plastidial enzyme functioning as DNA ligase remains unclear. However, it has been noted that AtLIG6 has a putative plastid-targeting peptide at the $N$ terminus and might therefore be targeted to plastids (Sunderland et al., 2006).

Cyanidioschyzon merolae has a single gene encoding DNA ligase. Cyanidioschyzon merolae DNA ligase 1 (CmLIG1) has two methionine residues in its $N$-terminal region and is targeted to both mitochondria and plastids when the transcript is translated from the first and second initiation codons (Moriyama et al., 2014). In our analysis, no nuclear localization was observed when the $N$-terminal peptide of CmLIG1 was fused with GFP. However, the protein subcellular localization prediction software WolfPSORT (http://wolfpsort.seq.cbrc.jp/) detected a nuclear localization signal in CmLIG1. Therefore, CmLIG1 appears to have triple localization in plastids, mitochondria, and the nucleus.

\section{SINGLE-STRANDED DNA (ssDNA)-BINDING PROTEIN}

An SSB, AtSSB1, was identified in A. thaliana (Edmondson et al., 2005). AtSSB1 is localized to mitochondria, but was also reported to be localized to chloroplasts in the review by Cupp and Nielsen (2014). AtSSB1 binds to ssDNA, but not to dsDNA, and stimulates RecA-mediated strand exchange activity.

Organellar ssDNA-binding proteins (OSBs) comprise the second class of SSBs in plants (Zaegel et al., 2006). OSBs have an SSB-like domain in the central region and one, two, or three C-terminal PDF motifs, which consist of 50-amino acids and are responsible for ssDNA binding. PDF motifs are conserved only in green plants, including Chlamydomonas reinhardtii. A. thaliana has four OSBs: AtOSB1 and 2 are localized to mitochondria and chloroplasts, respectively, whereas AtOSB3 is localized to both chloroplasts and mitochondria. AtOSB1 and AtOSB2 have been purified as recombinant proteins that showed preferential binding activity to ssDNA, as compared to dsDNA or RNA. Expression analysis of AtOSB1 using a $\beta$ glucuronidase (GUS) assay demonstrated that AtOSB1 is mainly expressed in gametophytic cells. T-DNA insertion mutation of the OSB1, OSB2, and OSB3 genes revealed that $o s b 1$ mutants accumulate homologous recombination products of mitochondrial DNA, whereas osb2 and osb3 mutants have no visible phenotype. These findings, together with the expression analysis for AtOSB1, indicate that AtOSB1 is involved in mitochondrial DNA recombination in gametophytic cells (Zaegel et al., 2006).

Replication protein A (RPA) is a nucleus-localized BBC in eukaryotes and is comprised of three subunits, RPA70, RPA32, and RPA14. The rice genome encodes three RPA70s, three RPA32s, and one RPA14. These RPA subunits combine in different variations to make three types of complexes: type A, B, and C. Among these 
RPA complexes, the type A complex is localized to chloroplasts in rice (Ishibashi et al., 2006).

The Cyanidioschyzon merolae genome encodes a single gene for SSB, but does not contain a gene for OSB. In our analysis, the SSB of Cyanidioschyzon merolae is localized only in the mitochondrion, unlike that of A. thaliana (Moriyama et al., 2014). We performed the localization analysis using a construct starting from the second methionine codon or starting from the ATA codon located upstream of the first methionine codon; however, none of the constructs showed plastid localization. We also examined the organellar localization of RPAs in Cyanidioschyzon merolae, and even though they have no extension sequence at the $N$-terminus, they were localized to the nucleus. Based on these findings, the plastidial SSB in red algae remains unidentified.

\section{PRIMER REMOVAL ENZYME}

In $E$. coli, RNA primers are removed by nick translation with the $5^{\prime}-3^{\prime}$ exonuclease and polymerase activities of DNA polymerase I (Langston etal., 2009; Sanyal and Doig, 2012). In contrast, RNaseH1 performs this role in human mitochondria (Kasiviswanathan et al., 2012). Although there are no reports of RNA primer removal enzymes that are specific to the organelles in green plants, two $5^{\prime}-3^{\prime}$ exonucleases $\left(5^{\prime}-3^{\prime} \mathrm{EXO} 1\right.$ and 2$)$ having sequence homology to the $5^{\prime}-3^{\prime}$ exonuclease domain of E. coli PolI are predicted to be localized to chloroplasts or mitochondria (Sato et al., 2003).

Cyanidioschyzon merolae has a gene with high sequence homology to bacterial PolI (Moriyama et al., 2008). The corresponding protein, CmPolI, contains $5^{\prime}-3^{\prime}$ exonuclease and polymerase domains. We demonstrated the plastid localization of CmPolI by immunoblotting and observation of a CmPolI-GFP fusion protein (Moriyama et al., 2008, 2014). Because CmPolI has low processive polymerase activity and no $3^{\prime}-5^{\prime}$ exonuclease activity, the enzyme appears to function in repair and primer removal by nick translation, similar to PolI in E. coli. We also showed that Cyanidioschyzon merolae RNase HII is localized to the mitochondrion, and that DNA2 nuclease/helicase and FEN1 are localized to the nucleus (Moriyama et al., 2014).

\section{PHYLOGENETIC DISTRIBUTION OF ORGANELLAR REPLICATIVE ENZYMES}

ORIGIN OF ENZYMES RELATED TO ORGANELLAR GENOME REPLICATION

Phylogenetic analyses of bacterial-type replicative enzymes have been performed (Moriyama et al., 2014). We previously suggested that POP did not originate from the PolI of $\alpha$-proteobacteria or cyanobacteria (Figure 1, Moriyama et al., 2008). However, the analyses indicated that red algal DnaB helicase and DnaG primase originated from cyanobacteria (Figure 3A). Gyrases A and $\mathrm{B}$ also originated from cyanobacteria in both green plants and red algae (Figure 3B). Type IA topoisomerase was derived from $\alpha$-proteobacteria in green plants and from cyanobacteria in red algae (Figure 3C). SSB and 5' $-3^{\prime}$ exonuclease/PolI originated from $\alpha$-proteobacteria in green plants and red algae (Figure $3 \mathrm{D}$ ). With regard to PolI, as green plants have enzymes with $5^{\prime}-3^{\prime}$ exonuclease domain, but lack $3^{\prime}-5^{\prime}$ exonuclease and DNA polymerase domains (Figure 3F), phylogenetic analysis of the $5^{\prime}-3^{\prime}$ exonuclease domain in bacteria and photosynthetic eukaryotes was performed (Figures 3D,E). These results suggest that the organelle replication apparatus of both green plants and red algae is composed of enzymes of various origins, including $\alpha$-proteobacteria, cyanobacteria, and eukaryotes.

\section{REPERTOIRE OF ENZYMES RELATED TO ORGANELLAR GENOME REPLICATION IN PLANTS AND ALGAE}

The enzymes related to organellar DNA replication and recombination in a species of angiosperm, fern, moss, filamentous terrestrial alga, two green algae, and two red algae are listed in Table 1. The proteins conserved in the all examined species are POP, TWINKLE, Gyrases, type IA-TOP1, TOP2, and LIG1. DnaB and DnaG are conserved only in red algae. The retention of SSBs is highly variable in photosynthetic eukaryotes. Bacterial-type SSB proteins are conserved in land plants and Cyanidioschyzon merolae, whereas OSB proteins are conserved among land plants, including A. thaliana, Physcomitrella patens, and Klebsormidium flaccidum. It was reported that OSB proteins contain a few PDF motifs in addition to an SSB-like domain (Zaegel et al., 2006). According to this classification, Physcomitrella patens and K. flaccidum have a single OSB, which contains one and two PDF motifs, respectively, in addition to the SSB-like domain. RECA and Whirly (WHY) are recombination-related proteins and are also not uniformly conserved in photosynthetic eukaryotes. For example, Selaginella moellendorffii and Porphyridium purpureum do not have RECA, red algae do not encode WHY, and Physcomitrella patens has neither RECA nor WHY. Conservation of origin-binding protein $(\mathrm{ODB})$ is more limited, as only land plants have this protein. Poll containing $5^{\prime}-3^{\prime}$ exonuclease and DNA polymerase domains is retained only in red algae. However, a protein with the $5^{\prime}-3^{\prime}$ exonuclease domain is found in photosynthetic eukaryotes, with the exception of Cyanidioschyzon merolae. Therefore, all photosynthetic eukaryotes contain proteobacteria-derived PolI. RNase $\mathrm{H}$ having high homology to RNase HII of Cyanidioschyzon merolae is conserved in most plants and algae, with the notable exception of A. thaliana. The observed distribution of enzymes that play key roles in replication indicates that they are essentially conserved in all plants and algae. In contrast, because recombination-related enzymes and SSBs are non-uniformly distributed among plants and algae, these enzymes are considered to exhibit high plasticity during evolution.

Based on the presence of enzymes related to organellar genome replication in plant genomes, we propose a model for the substitution of these enzymes in photosynthetic eukaryotes (Figure 4). In this model, the ancestor of photosynthetic eukaryotes, prior to its divergence into green and red lineages, contained POP, TWINKLE, DnaB, DnaG, gyrases, type-IA TOP1, TOP2, PolI, RNase HII, SSB, and LIG1. Several of these enzymes, including POP, TWINKLE, gyrases, type-IA TOP1, TOP2, LIG1, and PolI (or 5'-3' exonuclease), were retained by all plants. In the early green lineage, WHY was obtained, and mitochondrial TWINKLE became dually localized in mitochondria and plastids. However, the dual-localization of TWINKLE resulted in the loss of DnaB and DnaG in the green lineage. After the divergence of Chlorophyta, the ancestor of land plants obtained the SSBs, OSB, and ODB. The acquisition of these SSBs, in addition to WHY, in the 
A

DnaB and DnaG

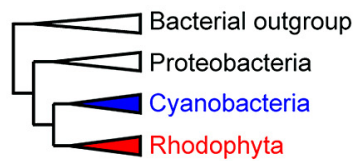

B Gyrase A and B

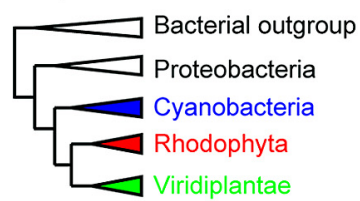

C TOP1 (type IA)

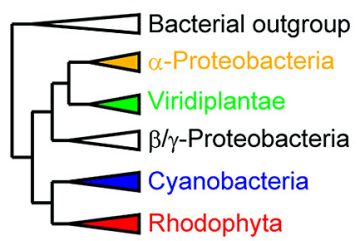

F
D SSB and DNA polymerase I

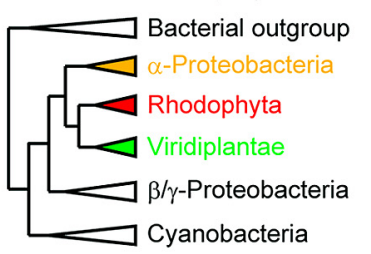

E

DNA polymerase I (5' -3' exonuclease domain)
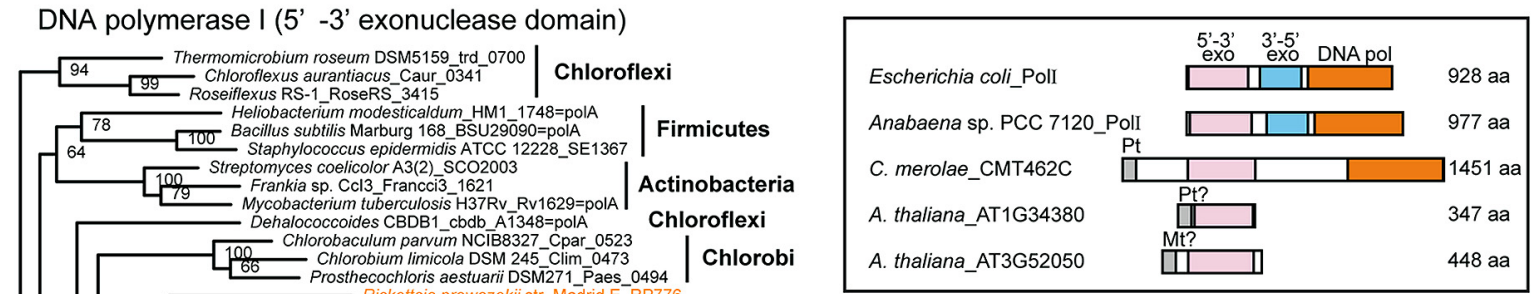

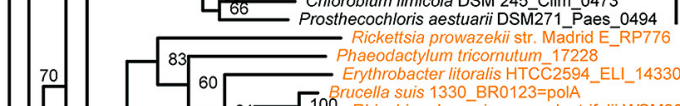

94

\section{$\frac{\pi}{2}$
$\frac{0}{0}$
$\frac{0}{0}$
$\frac{0}{0}$
$\frac{0}{0}$
$\frac{0}{0}$
$\frac{2}{1}$
$\frac{1}{1}$}

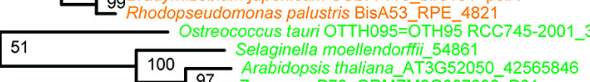

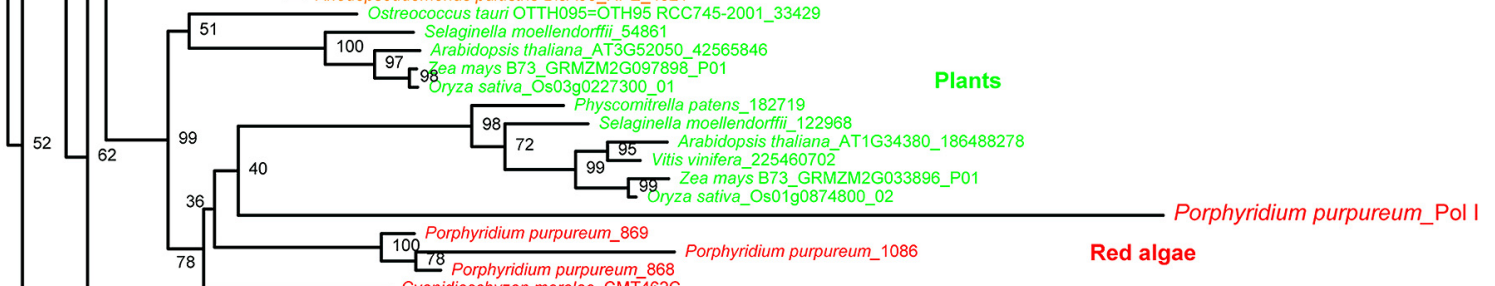

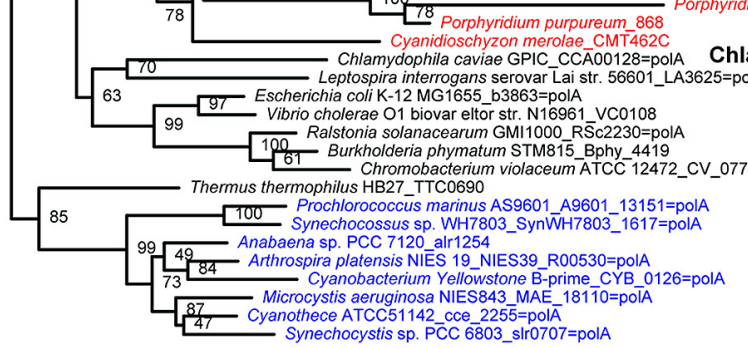

0.4

FIGURE 3 | Phylogenetic trees of enzymes related to organellar genome replication. Simplified phylogenetic trees (A-D). A detailed phylogenetic tree based on plant $5^{\prime}-3^{\prime}$ exonuclease and the $5^{\prime}-3^{\prime}$ exonuclease domains of bacterial Poll (E). Schematic comparison of the structure of Poll and plant $5^{\prime}-3^{\prime}$ exonuclease (F). Modified from Moriyama et al. (2014) with permission.

green lineage may have partially contributed to exploration of terrestrial habitats, as the high recombinant/repair activity of these enzymes would have potentially allowed the repair of DNA damaged by direct sunlight. The sets of RECA and WHY, and RECA and OSB were lost in Bryophyta and Pteridophyta, respectively, followed by the loss of RNase HII (homolog of Cyanidioschyzon merolae CMT626C) in Angiospermae. In red algae, most replication enzymes in the ancestor of photosynthetic eukaryotes are found in present-day species.

\section{CONCLUDING REMARKS}

In the past decade, most enzymes related to plastid and mitochondrial DNA replication in plants and algae have been identified.
These studies have revealed that the core enzymes and components involved replication are identical in the plastids and mitochondria of land plants. Because the nuclear genomes of green plants and algae encode these core replicative enzymes, such as POP, TWINKLE, gyrases, TOP1, TOP2, LIG1, and $5^{\prime}-3^{\prime}$ exonuclease, which frequently contain putative dual-targeting sequences at the $N$ terminus (Table 1), it is presumed that the green lineage contains a similar set of plastid and mitochondrial enzymes. In contrast, SSBs and recombination-related enzymes are not universally conserved in the green lineage, suggesting that these enzymes are possibly susceptible to exchange or loss during evolution, leading to the acquisition or creation of species-specific enzymes. Unlike the green lineage, red algae contain different replicative protein 


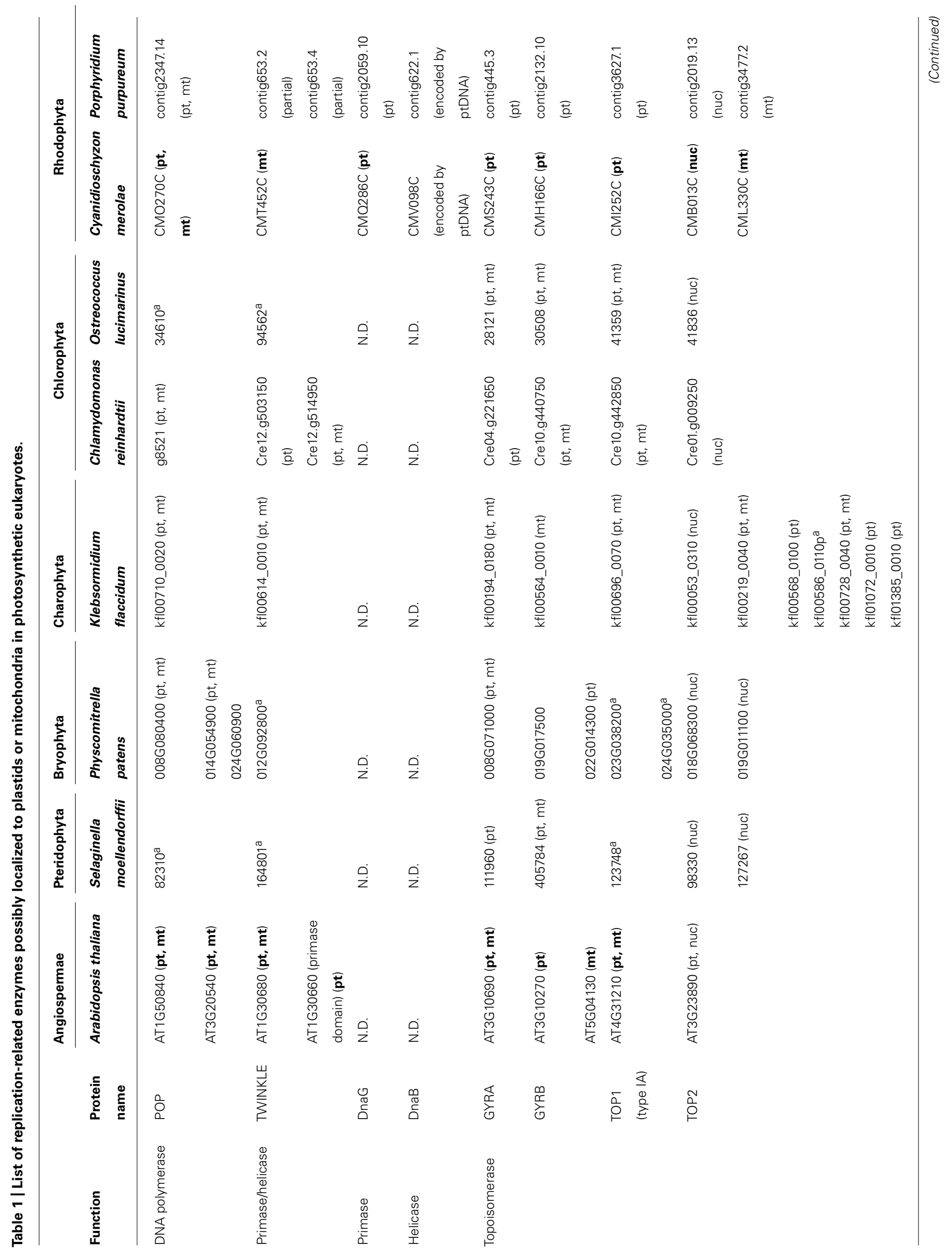



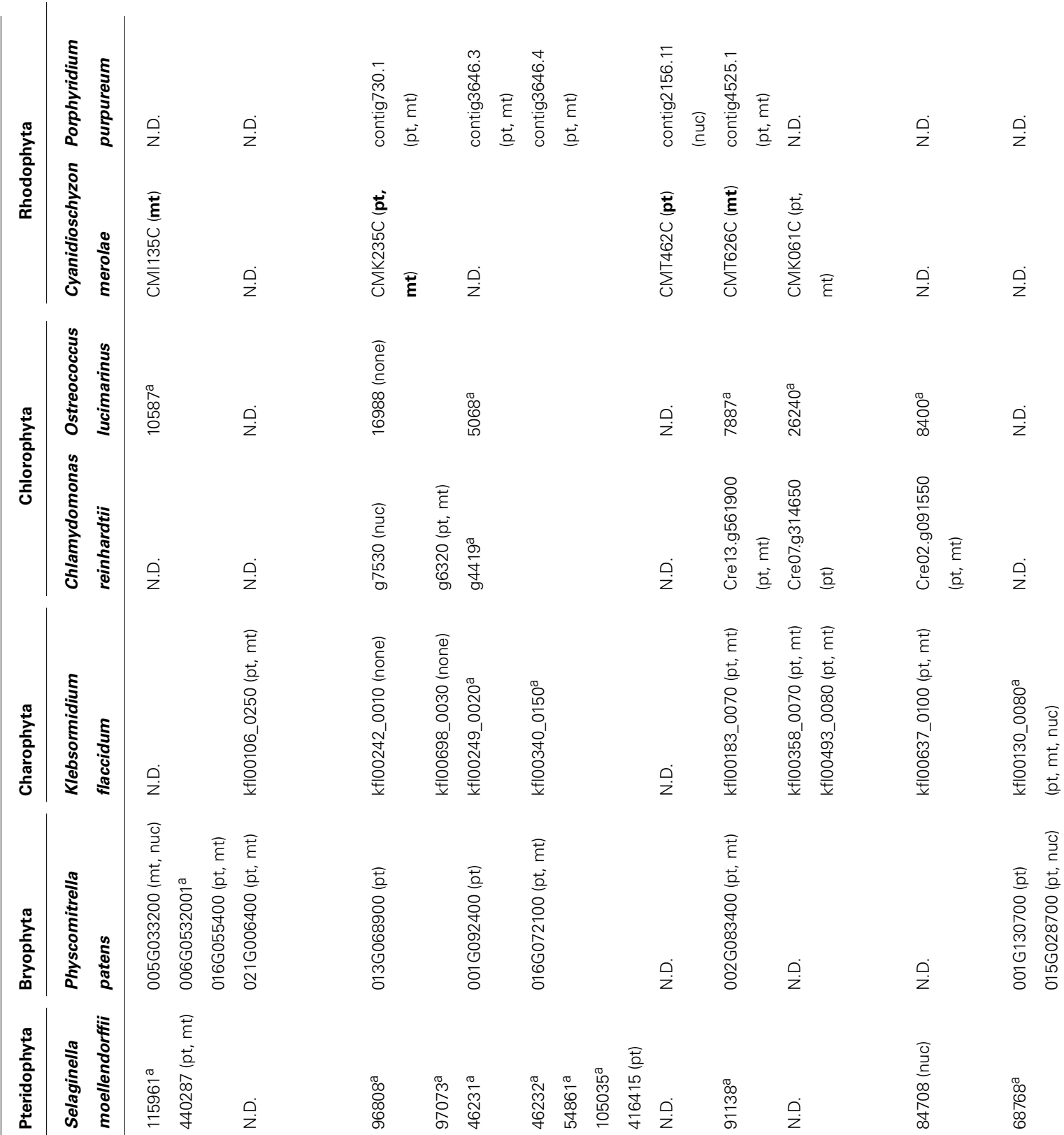

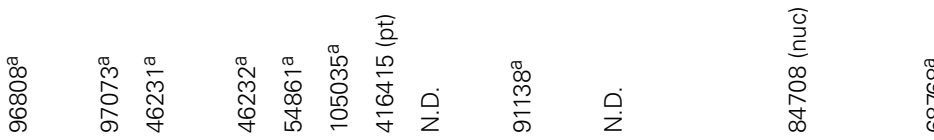

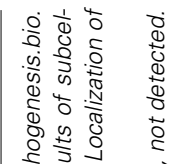

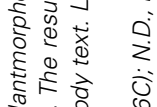

每

दो का

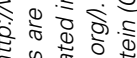

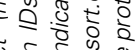

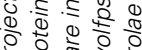

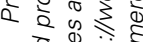

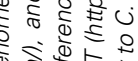

क्षे के के के

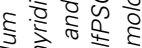

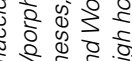

ह क व

엉 8

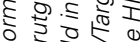

ब)

in

क्षे

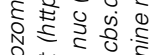

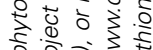

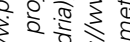

है हो है

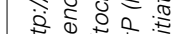

흘 है है

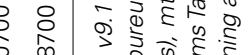

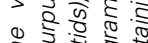

है क⿺辶一

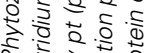

ते

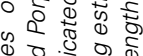

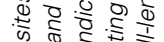

उं हों $\frac{0}{\pi} \frac{0}{\pi}$

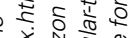

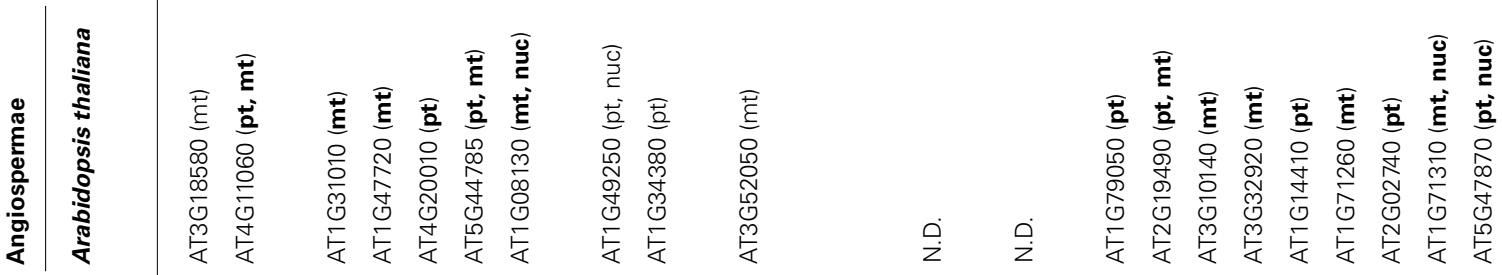

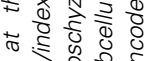

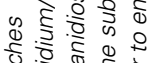

क्षे

के के के के :

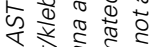

iे $\overline{\overline{0}}$

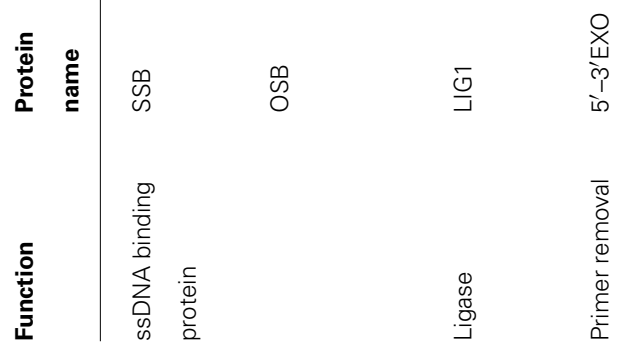

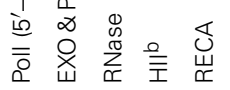

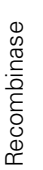

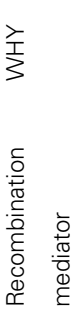

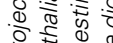

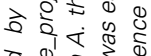

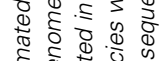

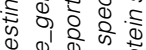

(2)

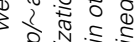

की

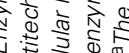




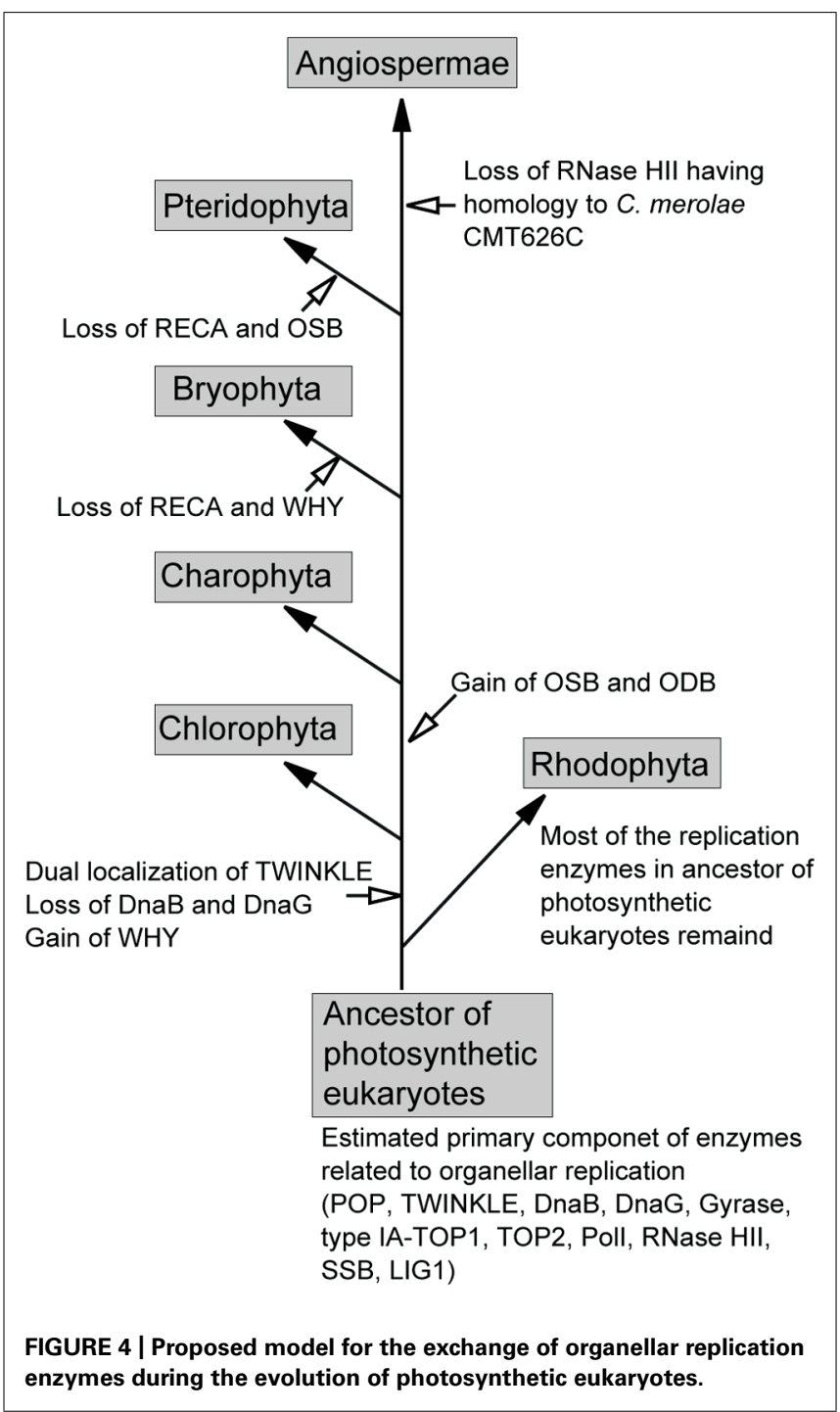

profiles in plastids and mitochondria. Red algal plastids contain numerous replication proteins that originated from cyanobacteria (Moriyama et al., 2014), suggesting that the mechanism of genome replication in these plastids might be similar to that found in bacteria.

To date, a number of organelle-localized enzymes have been identified. However, biochemical data are lacking for the majority of organellar replication enzymes in plants. The role of an enzyme predicted by homology searches against known enzymes might differ from its actual function or properties. For example, soybean plastid DNA replication ODB shares homology with bacterial and A. thaliana SSB, but only binds to dsDNA of the oriA sequence in plastid DNA, and not to ssDNA (Lassen et al., 2011).

The regulatory mechanisms controlling the initiation of plant organellar genome replication and the number of organellar DNA copies remains to be explored. Recently, chloroplast DNA replication was shown to be regulated by the cellular redox state in the green alga Chlamydomonas reinhardtii (Kabeya and Miyagishima, 2013). Specifically, chloroplast DNA replication was activated and inactivated by the addition of reducing and oxidative agents, respectively, in both in vivo and in vitro assays. Light-dependent genome replication was also reported in cyanobacteria, in which DCMU [3-(3,4-dichlorophenyl)-1,1-dimethylurea], an inhibitor of electron transport between the PSII complex and plastoquinone pool, inhibits DNA replication initiation, and DBMIB (2,5dibromo-3-isopropyl-6-methyl-p-benzoquinone), an inhibitor of electron transport between plastoquinone and cytochrome $b_{6} f$ complex, inhibits the initiation and elongation of replication (Watanabe et al., 2012; Ohbayashi et al., 2013). Thus, the lightmediated replication of plastid DNA in algae may have originated from cyanobacteria. However, organellar replication in land plants and multicellular plants appears to be regulated by other mechanisms. In land plants, the replication of organellar genomes is restricted to meristematic tissues, and is not associated with the cycle or organellar division (Hashimoto and Possingham, 1989; Fujie et al., 1993). These findings suggest that land plants have more complex regulatory mechanisms controlling the replication of organellar genomes than those operating in algae.

\section{ACKNOWLEDGMENTS}

This work was supported in part by Core Research for Evolutional Science and Technology (CREST) from the Japan Science and Technology Agency (JST), and Grants-in-Aid for Young Scientists (B) from the Japan Society for the Promotion of Science (JSPS; no. 25870155).

\section{REFERENCES}

Arnold, J., Smidansky, E., Moustafa, I., and Cameron, C. (2012). Human mitochondrial RNA polymerase: structure-function, mechanism and inhibition. Biochim. Biophys. Acta 1819, 948-960. doi: 10.1016/j.bbagrm.2012.04.002

Carrie, C., Kühn, K., Murcha, M., Duncan, O., Small, I., O’Toole, N., et al. (2009). Approaches to defining dual-targeted proteins in Arabidopsis. Plant J. 57, 11281139. doi: 10.1111/j.1365-313X.2008.03745.x

Carrie, C., and Small, I. (2013). A reevaluation of dual-targeting of proteins to mitochondria and chloroplasts. Biochim. Biophys. Acta 1833, 253-259. doi: 10.1016/j.bbamcr.2012.05.029

Chavalitshewinkoon-Petmitr, P., Chawprom, S., Naesens, L., Balzarini, J., and Wilairat, P. (2000). Partial purification and characterization of mitochondrial DNA polymerase from Plasmodium falciparum. Parasitol. Int. 49, 279-288. doi: 10.1016/S1383-5769(00)00057-X

Cho, H. S., Lee, S. S., Kim, K. D., Hwang, I., Lim, J., Park, Y., et al. (2004). DNA gyrase is involved in chloroplast nucleoid partitioning. Plant Cell 16, 2665-2682. doi: 10.1105/tpc.104.024281

Christensen, A., Lyznik, A., Mohammed, S., Elowsky, C., Elo, A., Yule, R., et al. (2005). Dual-domain, dual-targeting organellar protein presequences in Arabidopsis can use non-AUG start codons. Plant Cell 17, 2805-2816. doi: $10.1105 /$ tpc. 105.035287

Cupp, J. D., and Nielsen, B. L. (2013). Arabidopsis thaliana organellar DNA polymerase IB mutants exhibit reduced mtDNA levels with a decrease in mitochondrial area density. Physiol. Plant. 149, 91-103. doi: 10.1111/ppl. 12009

Cupp, J. D., and Nielsen, B. L. (2014). Minireview: DNA replication in plant mitochondria. Mitochondrion doi: 10.1016/j.mito.2014.03.008 [Epub ahead of print].

Diray-Arce, J., Liu, B., Cupp, J. D., Hunt, T., and Nielsen, B. L. (2013). The Arabidopsis Atlg30680 gene encodes a homologue to the phage T7 gp4 protein that has both DNA primase and DNA helicase activities. BMC Plant Biol. 13:36. doi: 10.1186/1471-2229-13-36

Edmondson, A. C., Song, D., Alvarez, L. A., Wall, M. K., Almond, D., McClellan, D. A., et al. (2005). Characterization of a mitochondrially targeted single-stranded DNA-binding protein in Arabidopsis thaliana. Mol. Genet. Genomics 273, 115122. doi: 10.1007/s00438-004-1106-5 
Evans-Roberts, K. M., Breuer, C., Wall, M. K., Sugimoto-Shirasu, K., and Maxwell, A. (2010). Arabidopsis thaliana GYRB3 does not encode a DNA gyrase subunit. PLoS ONE 5:e9899. doi: 10.1371/journal.pone.0009899

Fujie, M., Kuroiwa, H., Kawano, S., and Kuroiwa, T. (1993). Studies on the behavior of organelles and their nucleoids in the root apical meristem of Arabidopsis thaliana (L.) Col. Planta 189, 443-452. doi: 10.1007/BF00194444

Gualberto, J. M., Mileshina, D., Wallet, C., Niazi, A. K., Weber-Lotfi, F., and Dietrich, A. (2014). The plant mitochondrial genome: dynamics and maintenance. Biochimie 100, 107-120. doi: 10.1016/j.biochi.2013.09.016

Hashimoto, H., and Possingham, J. (1989). DNA levels in dividing and developing plastids in expanding primary leaves of Avena sativa. J. Exp. Bot. 40, 257-262. doi: $10.1093 / \mathrm{jxb} / 40.2 .257$

Holmes, A. M. (1981). Studies on the inhibition of highly purified calf thymus $8 \mathrm{~S}$ and 7.3S DNA polymerase alpha by aphidicolin. Nucleic Acids Res. 9, 161-168. doi: 10.1093/nar/9.1.161

Ishibashi, T., Kimura, S., and Sakaguchi, K. (2006). A higher plant has three different types of RPA heterotrimeric complex. J. Biochem. 139, 99-104. doi $10.1093 / \mathrm{jb} / \mathrm{mvj014}$

Itoh, R., Takahashi, H., Toda, K., Kuroiwa, H., and Kuroiwa, T. (1997). DNA gyrase involvement in chloroplast-nucleoid division in Cyanidioschyzon merolae. Eur. J. Cell Biol. 73, 252-258.

Kabeya, Y., and Miyagishima, S. (2013). Chloroplast DNA replication is regulated by the redox state independently of chloroplast division in Chlamy domonas reinhardtii. Plant Physiol. 161, 2102-2112. doi: 10.1104/pp.113. 216291

Kaguni, L. (2004). DNA polymerase gamma, the mitochondrial replicase. Annu. Rev. Biochem. 73, 293-320. doi: 10.1146/annurev.biochem.72.121801. 161455

Kasiviswanathan, R., Collins, T., and Copeland, W. (2012). The interface of transcription and DNA replication in the mitochondria. Biochim. Biophys. Acta 1819, 970-978. doi: 10.1016/j.bbagrm.2011.12.005

Kimura, S., Uchiyama, Y., Kasai, N., Namekawa, S., Saotome, A., Ueda, T., et al. (2002). A novel DNA polymerase homologous to Escherichia coli DNA polymerase I from a higher plant, rice (Oryza sativa L.). Nucleic Acids Res. 30, 1585-1592. doi: 10.1093/nar/30.7.1585

Kobayashi, Y., Kanesaki, Y., Tanaka, A., Kuroiwa, H., Kuroiwa, T., and Tanaka, K. (2009). Tetrapyrrole signal as a cell-cycle coordinator from organelle to nuclear DNA replication in plant cells. Proc. Natl. Acad. Sci. U.S.A. 106, 803-807. doi: 10.1073/pnas.0804270105

Korhonen, J., Pham, X., Pellegrini, M., and Falkenberg, M. (2004). Reconstitution of a minimal mtDNA replisome in vitro. EMBO J. 23, 2423-2429. doi: 10.1038/sj.emboj.7600257

Kornberg, A., and Baker, T. A. (1992). DNA Replication, 2nd Edn. New York: W. H. Freeman and Company.

Kühn, K., Bohne, A., Liere, K., Weihe, A., and Börner, T. (2007). Arabidopsis phagetype RNA polymerases: accurate in vitro transcription of organellar genes. Plant Cell 19, 959-971. doi: 10.1105/tpc.106.046839

Langston, L. D., Indiani, C., and O'Donnell, M. (2009). Whither the replisome: emerging perspectives on the dynamic nature of the DNA replication machinery. Cell Cycle 8, 2686-2691. doi: 10.4161/cc.8.17.9390

Lassen, M. G., Kochhar, S., Kocchar, S., and Nielsen, B. L. (2011). Identification of a soybean chloroplast DNA replication origin-binding protein. Plant Mol. Biol. 76, 463-471. doi: 10.1007/s11103-011-9736-6

Lecrenier, N., and Foury, F. (2000). New features of mitochondrial DNA replication system in yeast and man. Gene 246, 37-48. doi: 10.1016/S0378-1119(00)00107-4

Leinbach, S. S., Reno, J. M., Lee, L. F., Isbell, A. F., and Boezi, J. A. (1976). Mechanism of phosphonoacetate inhibition of herpesvirus-induced DNA polymerase. Biochemistry 15, 426-430. doi: 10.1021/bi00647a029

Maréchal, A., and Brisson, N. (2010). Recombination and the maintenance of plant organelle genome stability. New Phytol. 186, 299-317. doi: 10.1111/j.14698137.2010.03195.x

Matsuzaki, M., Misumi, O., Shin-I, T., Maruyama, S., Takahara, M., Miyagishima, S. Y., et al. (2004). Genome sequence of the ultrasmall unicellular red alga Cyanidioschyzon merolae 10D. Nature 428, 653-657. doi: 10.1038/nature02398

Mori, Y., Kimura, S., Saotome, A., Kasai, N., Sakaguchi, N., Uchiyama, Y., et al. (2005). Plastid DNA polymerases from higher plants, Arabidopsis thaliana. Biochem. Biophys. Res. Commun. 334, 43-50. doi: 10.1016/j.bbrc.2005. 06.052
Moriyama, T., and Sato, N. (2013). "The plant and protist organellar DNA replication enzyme POP showing up in place of DNA polymerase gamma may be a suitable antiprotozoal drug target," in The Mechanisms of DNA Replication, ed. D. Stuart (Rijeka: InTech), 287-311.

Moriyama, T., Tajima, N., Sekine, K., and Sato, N. (2014). Localization and phylogenetic analysis of enzymes related to organellar genome replication in the unicellular rhodophyte Cyanidioschyzon merolae. Genome Biol. Evol. 6, 228-237. doi: $10.1093 /$ gbe/evu009

Moriyama, T., Terasawa, K., Fujiwara, M., and Sato, N. (2008). Purification and characterization of organellar DNA polymerases in the red alga Cyanidioschyzon merolae. FEBS J. 275, 2899-2918. doi: 10.1111/j.1742-4658.2008.06426.x

Moriyama, T., Terasawa, K., and Sato, N. (2011). Conservation of POPs, the plant organellar DNA polymerases, in eukaryotes. Protist 162, 177-187. doi: 10.1016/j.protis.2010.06.001

Moriyama, T., Terasawa, K., Sekine, K., Toyoshima, M., Koike, M., Fujiwara, M., et al. (2010). Characterization of cell-cycle-driven and light-driven gene expression in a synchronous culture system in the unicellular rhodophyte Cyanidioschyzon merolae. Microbiology 156, 1730-1737. doi: 10.1099/mic.0. 037754-0

Nielsen, B. L., Cupp, J. D., and Brammer, J. (2010). Mechanisms for maintenance, replication, and repair of the chloroplast genome in plants. J. Exp. Bot. 61, 25352537. doi: 10.1093/jxb/erq163

Ohbayashi, R., Watanabe, S., Kanesaki, Y., Narikawa, R., Chibazakura, T., Ikeuchi, M., etal. (2013). DNA replication depends on photosynthetic electron transport in cyanobacteria. FEMS Microbiol. Lett. 344, 138-144. doi: 10.1111/1574-6968.12166

Ono, Y., Sakai, A., Takechi, K., Takio, S., Takusagawa, M., and Takano, H. (2007). NtPolI-like1 and NtPolI-like2, bacterial DNA polymerase I homologs isolated from BY-2 cultured tobacco cells, encode DNA polymerases engaged in DNA replication in both plastids and mitochondria. Plant Cell Physiol. 48, 1679-1692. doi: $10.1093 / \mathrm{pcp} / \mathrm{pcm} 140$

Parent, J., Lepage, E., and Brisson, N. (2011). Divergent roles for the two PolIlike organelle DNA polymerases of Arabidopsis. Plant Physiol. 156, 254-262. doi: 10.1104/pp.111.173849

Parsons, P., and Simpson, M. V. (1967). Biosynthesis of DNA by isolated mitochondria: incorporation of thymidine triphosphate-2-C-14. Science 155, 91-93. doi: $10.1126 /$ science.155.3758.91

Sakai, A. (2001). In vitro transcription/DNA synthesis using isolated organellenuclei: application to the analysis of the mechanisms that regulate organelle genome function. J. Plant Res. 114, 199-211. doi: 10.1007/PL00013984

Sakai, A., Suzuki, T., Nagata, N., Sasaki, N., and Miyazawa, Y. (1999). Comparative analysis of DNA synthesis activity in plastid-nuclei and mitochondrial-nuclei simultaneously isolated from cultured tobacco cells. Plant Sci. 140, 9-19. doi: $10.1016 /$ S0168-9452(98)00207-6

Sanyal, G., and Doig, P. (2012). Bacterial DNA replication enzymes as targets for antibacterial drug discovery. Expert Opin. Drug Discov. 7, 327-339. doi: $10.1517 / 17460441.2012 .660478$

Sato, N., Terasawa, K., Miyajima, K., and Kabeya, Y. (2003). Organization, developmental dynamics, and evolution of plastid nucleoids. Int. Rev. Cytol. 232, 217-262. doi: 10.1016/S0074-7696(03)32006-6

Shiraki, K., Okuno, T., Yamanishi, K., and Takahashi, M. (1989). Phosphonoacetic acid inhibits replication of human herpesvirus-6. Antiviral Res. 12, 311-318. doi: 10.1016/0166-3542(89)90058-2

Shutt, T., and Gray, M. (2006). Twinkle, the mitochondrial replicative DNA helicase, is widespread in the eukaryotic radiation and may also be the mitochondrial DNA primase in most eukaryotes. J. Mol. Evol. 62, 588-599. doi: 10.1007/s00239-0050162-8

Spelbrink, J. N., Li, F. Y., Tiranti, V., Nikali, K., Yuan, Q. P., Tariq, M., et al. (2001). Human mitochondrial DNA deletions associated with mutations in the gene encoding Twinkle, a phage T7 gene 4-like protein localized in mitochondria. Nat. Genet. 28, 223-231. doi: 10.1038/90058

Spencer, D., and Whitfeld, P. R. (1967). DNA synthesis in isolated chloroplasts. Biochem. Biophys. Res. Commun. 28, 538-542. doi: 10.1016/0006291X(67)90347-6

Sunderland, P. A., West, C. E., Waterworth, W. M., and Bray, C. M. (2004). Choice of a start codon in a single transcript determines DNA ligase 1 isoform production and intracellular targeting in Arabidopsis thaliana. Biochem. Soc. Trans. 32, 614-616. doi: 10.1042/BST0320614 
Sunderland, P. A., West, C. E., Waterworth, W. M., and Bray, C. M. (2006). An evolutionarily conserved translation initiation mechanism regulates nuclear or mitochondrial targeting of DNA ligase 1 in Arabidopsis thaliana. Plant J. 47, 356-367. doi: 10.1111/j.1365-313X.2006.02791.x

Suzuki, K., Ehara, T., Osafune, T., Kuroiwa, H., Kawano, S., and Kuroiwa, T. (1994). Behavior of mitochondria, chloroplasts and their nuclei during the mitotic cycle in the ultramicroalga Cyanidioschyzon merolae. Eur. J. Cell Biol. 63, 280-288.

Takeuchi, R., Kimura, S., Saotome, A., and Sakaguchi, K. (2007). Biochemical properties of a plastidial DNA polymerase of rice. Plant Mol. Biol. 64, 601-611. doi: 10.1007/s11103-007-9179-2

Taylor, R. M., Hamer, M. J., Rosamond, J., and Bray, C. M. (1998). Molecular cloning and functional analysis of the Arabidopsis thaliana DNA ligase I homologue. Plant J. 14, 75-81. doi: 10.1046/j.1365-313X.1998.00094.x

Tewari, K. K., and Wildman, S. G. (1967). DNA polymerase in isolated tobacco chloroplasts and nature of the polymerized product. Proc. Natl. Acad. Sci. U.S.A. 58, 689-696. doi: 10.1073/pnas.58.2.689

Wall, M., Mitchenall, L., and Maxwell, A. (2004). Arabidopsis thaliana DNA gyrase is targeted to chloroplasts and mitochondria. Proc. Natl. Acad. Sci. U.S.A. 101, 7821-7826. doi: 10.1073/pnas.0400836101

Wanrooij, S., and Falkenberg, M. (2010). The human mitochondrial replication fork in health and disease. Biochim. Biophys. Acta 1797, 1378-1388. doi: 10.1016/j.bbabio.2010.04.015

Wanrooij, S., Fusté, J., Farge, G., Shi, Y., Gustafsson, C., and Falkenberg, M. (2008). Human mitochondrial RNA polymerase primes lagging-strand DNA synthesis in vitro. Proc. Natl. Acad. Sci. U.S.A. 105, 11122-11127. doi: 10.1073/pnas.0805399105

Watanabe, S., Ohbayashi, R., Shiwa, Y., Noda, A., Kanesaki, Y., Chibazakura, T., et al. (2012). Light-dependent and asynchronous replication of cyanobacterial multi-copy chromosomes. Mol. Microbiol. 83, 856-865. doi: 10.1111/j.13652958.2012.07971.x
Weiser, T., Gassmann, M., Thömmes, P., Ferrari, E., Hafkemeyer, P., and Hübscher, U. (1991). Biochemical and functional comparison of DNA polymerases alpha, delta, and epsilon from calf thymus. J. Biol. Chem. 266, 10420-10428.

Williams, A. J., Wernette, C. M., and Kaguni, L. S. (1993). Processivity of mitochondrial DNA polymerase from Drosophila embryos. Effects of reaction conditions and enzyme purity. J. Biol. Chem. 268, 24855-24862.

Wintersberger, E. (1966). Occurrence of a DNA-polymerase in isolated yeast mitochondria. Biochem. Biophys. Res. Commun. 25, 1-7. doi: 10.1016/0006291X(66)90630-9

Zaegel, V., Guermann, B., Le Ret, M., Andrés, C., Meyer, D., Erhardt, M., et al. (2006). The plant-specific ssDNA binding protein OSB1 is involved in the stoichiometric transmission of mitochondrial DNA in Arabidopsis. Plant Cell 18, 3548-3563. doi: $10.1105 /$ tpc. 106.042028

Conflict of Interest Statement: The authors declare that the research was conducted in the absence of any commercial or financial relationships that could be construed as a potential conflict of interest.

Received: 22 July 2014; paper pending published: 16 August 2014; accepted: 30 August 2014; published online: 17 September 2014.

Citation: Moriyama T and Sato N (2014) Enzymes involved in organellar DNA replication in photosynthetic eukaryotes. Front. Plant Sci. 5:480. doi: 10.3389/fpls.2014.00480 This article was submitted to Plant Physiology, a section of the journal Frontiers in Plant Science.

Copyright (c) 2014 Moriyama and Sato. This is an open-access article distributed under the terms of the Creative Commons Attribution License (CC BY). The use, distribution or reproduction in other forums is permitted, provided the original author(s) or licensor are credited and that the original publication in this journal is cited, in accordance with accepted academic practice. No use, distribution or reproduction is permitted which does not comply with these terms. 